\title{
Exploiting azafulvenium methides chemistry
}

\author{
Teresa M. V. D. Pinho e Melo \\ Departamento de Química, Universidade de Coimbra, 3004-535 Coimbra, Portugal \\ E-mail: tmelo@ci.uc.pt
}

\begin{abstract}
The synthesis of heterocycles via reactive intermediates, (e.g. azadienes, münchnones, aza- and diazafulvenium methides) generated from 1,3-thiazolidines is described. The use of thiazolidines' diastereoselective reactions for the synthesis of chiral heterocyclic compounds is also reported.
\end{abstract}

Keywords: Thiazolidines, bis(enamines), 1,3-thiazolidine-annulated systems, pyrrolo[1,2-c]thiazoles, azadienes, azafulvenium methides, diazafulvenium methides

\section{Table of Contents}

1. 2-Aza-1,3-butadienes or their tautomers from 1,3-thiazolidine-4-carboxylic acids

2. Synthesis of 1,3-thiazolidine-annulated systems

3. Dipoles from 1,3-thiazolidine-4-carboxylic acids

3.1 Cycloaddition strategy to chiral pyrrolo[1,2-c]thiazoles

3.2 Generation and Reactivity of Azafulvenium Methides

\section{Introduction}

1,3-Thiazolidine-4-carboxylic acids have proven to be useful building blocks in organic synthesis. The most interesting aspect of their reactivity is the possibility of carrying out diastereoselective reactions thus allowing the development of synthetic routes to chiral heterocycles. Of particular interest is also the use of 1,3-thiazolidine-4-carboxylic acids as precursors of reactive intermediates (e.g. azadienes or dipoles), which widen the type of structures that can be made available from these heterocycles. In the recent past, we have explored both approaches to new heterocyclic compounds and some illustrative examples of this chemistry will be presented in this paper. Particular emphasis will be given to our more recent research work, the generation and reactivity of azafulvenium methide systems. 


\section{2-Aza-1,3-butadienes or their tautomers from 1,3-thiazolidine-4-carboxylic acids}

The Diels-Alder reaction of acyclic 2-azadienes is a useful method for the preparation of pyridines, dihydropyridines and tetrahydropyridines. $N$-Arylidenedehydroalanine methyl esters had already been prepared in 1979 by Öhler and Schmidt, by the reaction of thiazolidine esters with silver carbonate and DBU. ${ }^{1}$ This synthetic strategy for the generation of the 2-azadienes 2a2f from the corresponding thiazolidines 1a-1f was further explored (Scheme 1). These intermediates can participate as 2-azadienes in Diels-Alder reactions with a range of dienophiles. The azadiene 2a show a particular reactivity pattern since it reacts with both electron deficient and electron rich dienophiles. ${ }^{2}$

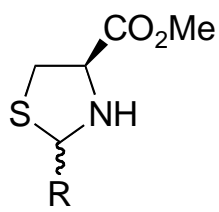

1

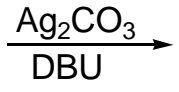

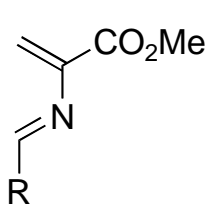

2

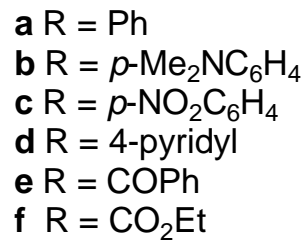

f $\mathrm{R}=\mathrm{CO}_{2} \mathrm{Et}$

\section{Scheme 1}

In fact, the azadiene 2a, generated in situ from the thiazolidine 1a in the presence of a large excess of but-3-en-2-one, leads to the formation of three compounds in an overall yield of $76 \%$. On the other hand, the same azadiene reacts with $N$-cyclohex-1-enylpyrrolidine with the formation of the cycloadducts 6 (37\%) and 7 (20\%) (Scheme 2). ${ }^{2}$

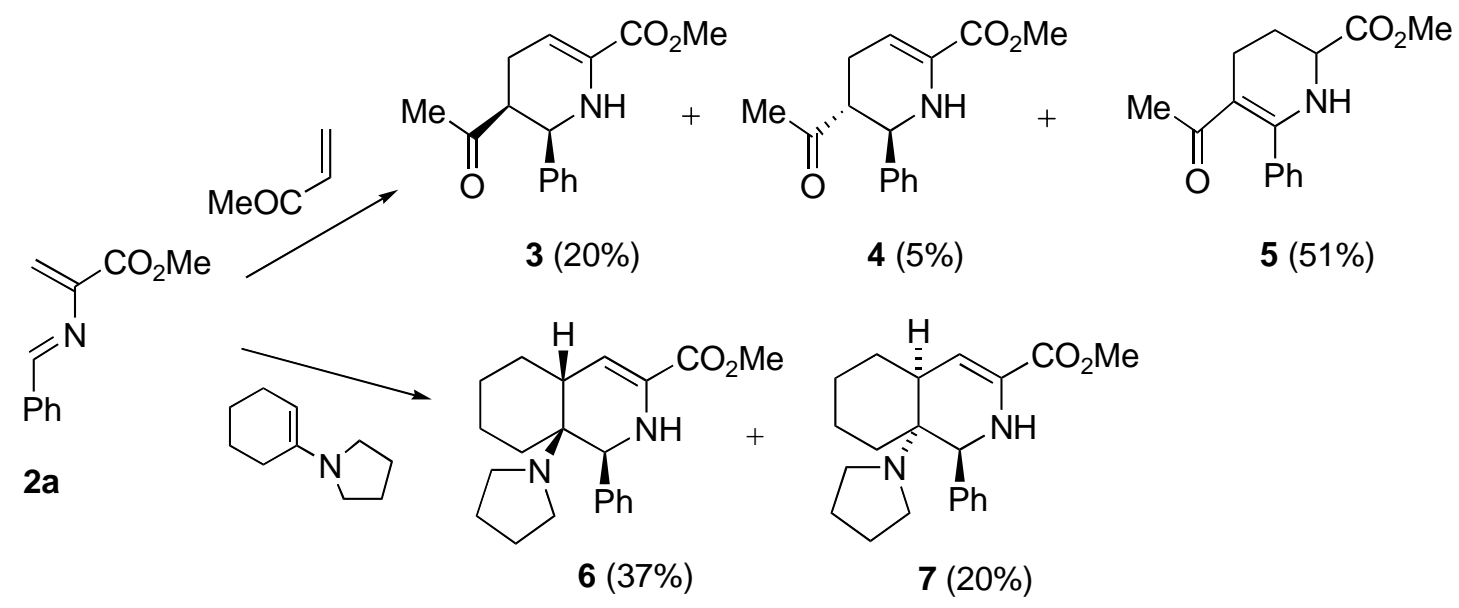

Scheme 2 
The unusual reactivity of azadiene 2a, characterized by the participation in both the normal and inverse Diels-Alder reaction, can be attributed to the fact that the HOMO and LUMO energy levels are rather close as indicate by AM1 calculations. The AM1 calculated polarization of the relevant frontier orbitals of azadiene 2a shows a higher contour value at C-4 than at C-1 in both LUMO and HOMO orbitals. This polarization explains the observed regioselectivity in the normal and inverse Diels-Alder reactions of this compound. On the other hand, the calculations predict both orbitals to be nearly symmetrical with respect to the $\mathrm{C}=\mathrm{N}-\mathrm{C}=\mathrm{C}$ plane, a result which is in agreement with the fact that no endo/exo selectivity has been experimentally observed. ${ }^{3}$

The azadienes (1a and $\mathbf{8}$ ) exclusively act as dienophiles in the reaction with cyclopentadiene and these compounds then undergo an aza Cope rearrangement (a 2-aza-[3,3]sigmatropic shift) at room temperature, followed by prototropy to give $\mathbf{1 1}$. The cycloadditions of 1-(benzylideneamino)acrylates 2a with cyclopentadiene gives two products the norbornene ester 10a and the tetrahydropyridine ester 11a. When allowed to stand in solution at room temperature for 10 days the product was found to consist of only a single component, compound 11a. A similar result was obtained starting from thiazolidine 8. In fact, compound $\mathbf{1 1 b}$ was also prepared by heating a solution of the Schiff base $\mathbf{1 0 b}$ in toluene (Scheme 3). ${ }^{4}$

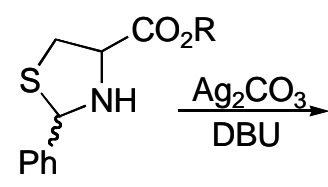

$1 \mathrm{a}(\mathrm{R}=\mathrm{Me})$ $8(\mathrm{R}=\mathrm{Et})$

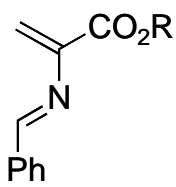

$2 a(R=M e)$ $9(R=E t)$
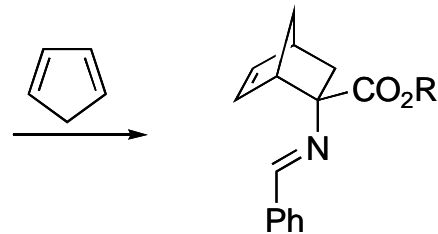

$10 \mathbf{a}(\mathrm{R}=\mathrm{Me})$ $10 b(R=E t)$

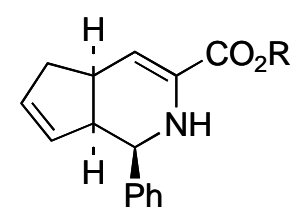

$11 \mathrm{a}(\mathrm{R}=\mathrm{Me})$

11b $(R=E t)$

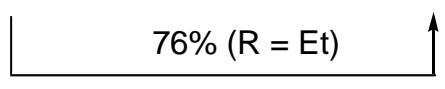

Toluene, $\Delta, 12 \mathrm{~h}$

\section{Scheme 3}

Thiazolidines 12 react with silver carbonate and DBU to give isolable cross-conjugated bis(enamines) 14, the more stable tautomers of the azadienes 13 (Scheme 4). ${ }^{5}$ The diester 14a has been also prepared from methyl $\beta$-halo- $\alpha$-aminopropionate hydrohalides by reaction with bases. ${ }^{6}$ Other cross-conjugated bis(enamines) of this type have been produced by thermal rearrangement of vinylaziridines. ${ }^{7}$ These compounds undergo an interesting photocyclization to 3,4-dihydropyrroles which can be intercepted, as 1,3-dipoles, in cycloaddition reactions with alkenes and alkynes. ${ }^{6,7,8}$ Compound 14a is also reported to react as an electrophile with hydrazines ${ }^{9}$ and with primary amines, ${ }^{10}$ giving hydrazones and imines of methyl pyruvate as products. The diester 14a reacts with DDQ to give a single product in high yield, a 1:1 adduct of the diester and DDQ (15), which structure was established by X-ray crystallography. Reaction of the diester 14a with methyl vinyl ketone gives the tetrahydropyridine $\mathbf{1 6}$ in moderate yield. The 
formation of this product can be rationalized as a conjugate addition-cyclization sequence, somewhat analogous to the Hantzsch dihydropyridine synthesis (Scheme 4). ${ }^{5}$

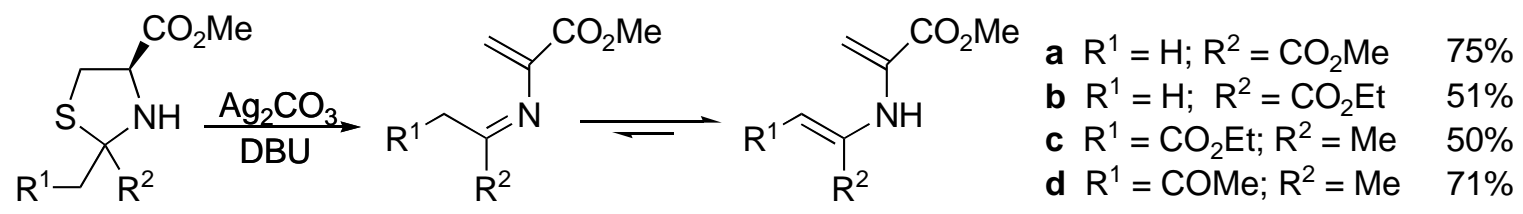

12

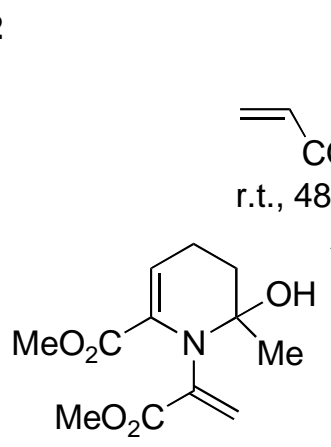

$1640 \%$ (from 14a)
13

14

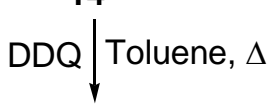

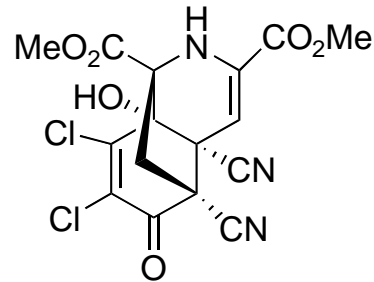

$1596 \%$ (from 14a)

\section{Scheme 4}

\section{Synthesis of 1,3-thiazolidine-annulated systems}

The synthesis of tricyclic isoindole derivatives from $L$-cysteine has been reported. The reaction of $L$-cysteine methyl ester with 2-carboxybenzaldehyde or 2-acetylbenzoic acid results in the direct diastereoselective synthesis of (3R,9bS)-5-oxo-2,3,5,9b-tetrahydro-thiazolo[2,3a]isoindole-3-carboxylate 18a and (3R,9bS)-9b-methyl-5-oxo-2,3,5,9b-tetrahydrothiazolo[2,3a]isoindole-3-carboxylate $\mathbf{1 8 b}$, respectively (Scheme 5). ${ }^{11}$ These compounds can be converted into the corresponding acids (19). The synthesis of compound 18a has also been reported by Allin and co-workers using more drastic reaction conditions ${ }^{12}$ and compound 19a can also be obtain directly from the reaction of 2-carboxybenzaldehyde with cysteine hydrochloride in the presence of pyridine. ${ }^{13}$ The sealed tube thermolysis of $\mathbf{1 9}$ in acetic anhydride gives 3-methylene2,5-dioxo-3H,9bH-oxazolo[2,3-a]isoindoles 20. The isoindole derivatives (20) represent a new member of a class of compounds having a significant number of applications. ${ }^{14}$ On flash vacuum pyrolysis compounds 19 undergo decarboxylation to the corresponding chiral (9bS)-5-oxo2,3,5,9b-tetrahydrothiazolo[2,3-a]isoindoles (21) in moderate yields. ${ }^{11 b}$ Compounds 21 have been prepared before from the reaction of carboxybenzaldehyde or 2-acetylbenzoic acid with 2aminoethanethiol. However, they were obtained as racemic mixtures. ${ }^{12,13,15}$ Some 5-oxo2,3,5,9b-tetrahydrothiazolo[2,3-a]isoindoles substituted at C-9 with aryl and heteroaromatic groups have also been prepared as racemic mixtures although the separation of both enantiomers can be achieved by chromatography on cellulose triacetate. ${ }^{14 \mathrm{~b}}$ 


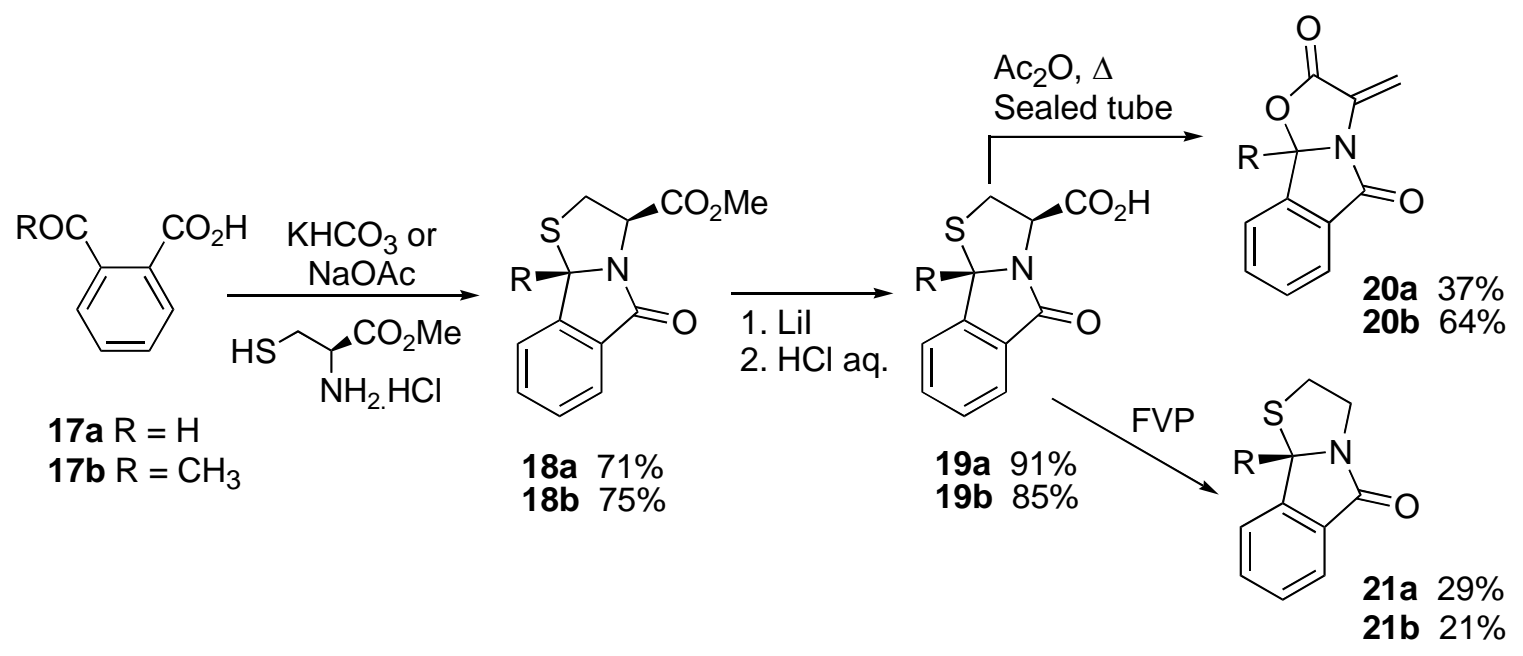

\section{Scheme 5}

\section{Dipoles from 1,3-thiazolidine-4-carboxylic acids}

\subsection{Cycloaddition strategy to chiral pyrrolo[1,2-c]thiazoles}

2-Substituted-1,3-thiazolidine-4-carboxylates are obtained from the reaction of aldehydes and $L$ cysteine esters in a process where a new chiral center at the C-2 position of the thiazolidine is created leading to a mixture of the $(2 S, 4 R)$ - and $(2 R, 4 R)$-diastereoisomers. The acylation of the diastereoisomeric mixture can lead to the selective synthesis of $N$-acyl-2-substituted-1,3thiazolidine-4-carboxylates as pure stereoisomers with $(2 R, 4 R)$ or $(2 S, 4 R)$ stereochemistry depending on the reaction conditions. In fact 2-substituted-1,3-thiazolidine-4-carboxylates can undergo selective inversion at $\mathrm{C}-2$ through a mechanism involving the opening of the ring but the protection with the acyl group prevents this epimerization and allows the isolation of pure diastereoisomers. ${ }^{16}$ The existing chiral center(s) in 1,3-thiazolidine-4-caboxylic acids allows diastereoselective reactions to occur, and these have been widely used for various synthetic purposes.

Györgydeák and co-workers ${ }^{17}$ have shown that chiral 3-substituted pyrrolo[1.2-c]thiazole6,7-dicarboxylates (22) can be obtained from 2-substituted- $N$-acyl-1,3-thiazolidine-4-carboxylic acids with high enantiomeric excess. The chirality at C-4 of the thiazolidine is lost and the chirality at C-2 (C-3 in the product) is retained (Scheme 6).

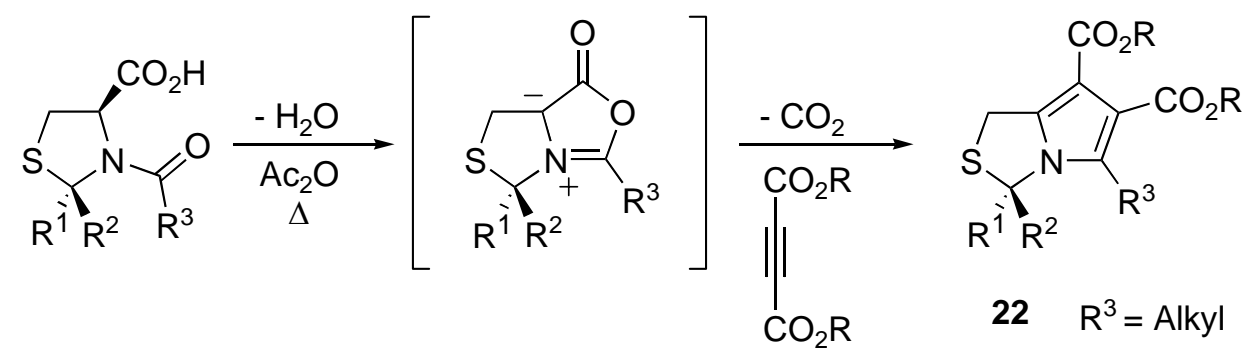

\section{Scheme 6}


The münchnones cycloaddition strategy to chiral pyrrolo[1,2-c]thiazoles, a class of compounds with potential biological activity, has been further explored. ${ }^{18}$ In our work we observed that starting from 2-phenylthiazolidine-4-carboxylic acid as a mixture of $2 R, 4 R$ - and 2S,4R-diastereoisomers, chiral 1H,3H-pyrrolo[1,2-c]thiazole derivatives were obtained. The thiazolidine was heated in a solution of acetic anhydride in the presence of a dipolarophile. Under these reaction conditions the stereoselective $N$-acylation occurs in situ, followed by the intermolecular dipolar cycloaddition giving chiral products with $R$ configuration (23). The reaction with methyl propiolate gave the regioisomer $\mathbf{2 3 b}$ exclusively. Heating 2phenylthiazolidine-4-carboxylic acid in acetic anhydride in the presence of alkyl vinyl ketones two products are obtained, the expected (3R)-7-acetyl-3-phenyl-5-methyl-1H,3H-pyrrolo[1,2c]thiazoles 24 and the spiro compounds 25 (Scheme 7).

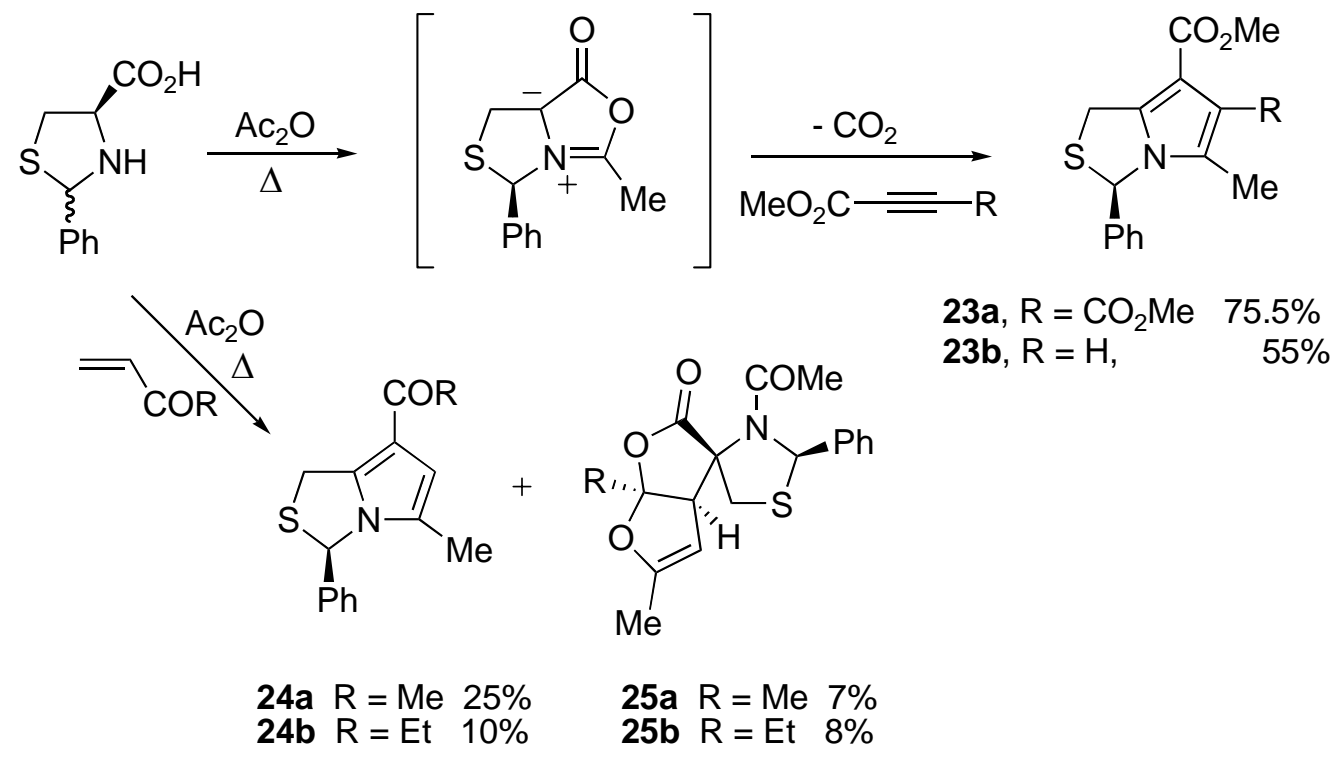

\section{Scheme 7}

$N$-Benzoyl-1,3-thiazolidines can also be used as precursors of $1 H, 3 H$-pyrrolo[1,2c]thiazole derivatives. In fact, the dipolar cycloadditions of (5R)-3-aryl- and (5S)-3-aryl-5phenyl-5H,7H-thiazolo-[3,4-c] oxazol-4-ium-1-olates 27 with dimethyl acetylene-dicarboxylate leads to the synthesis of $1 H, 3 H$-pyrrolo[1,2-c]thiazoles (28) in very high yield (Scheme 8). ${ }^{19}$ 


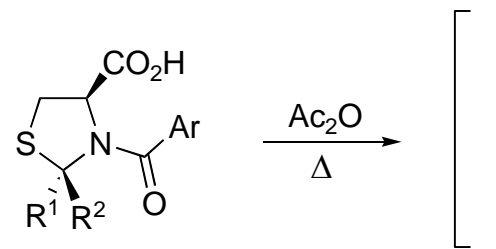

26

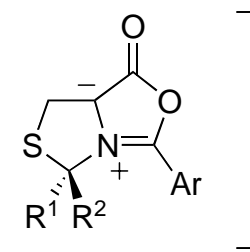

27

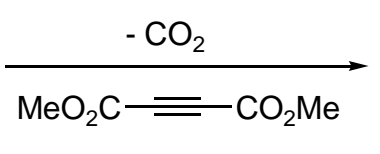

$\mathrm{MeO}_{2} \mathrm{C}=\mathrm{CO}_{2} \mathrm{Me}$<smiles>[R]C1SCc2c(C(C)=O)c(C(C)=O)c([Al])n21</smiles>

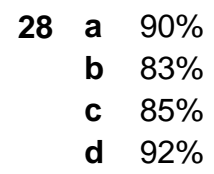

a $\mathrm{R}^{1}=\mathrm{H} ; \mathrm{R}^{2}=\mathrm{Ph} ; \mathrm{Ar}=\mathrm{Ph}$

b $\mathrm{R}^{1}=\mathrm{Ph} ; \mathrm{R}^{2}=\mathrm{H} ; \mathrm{Ar}=\mathrm{Ph}$

c $\mathrm{R}^{1}=\mathrm{H} ; \mathrm{R}^{2}=\mathrm{Ph} ; \mathrm{Ar}=\mathrm{C}_{6} \mathrm{H}_{4} \mathrm{OMe}-p$

d $\mathrm{R}^{1}=\mathrm{Ph} ; \mathrm{R}^{2}=\mathrm{H} ; \mathrm{Ar}=\mathrm{C}_{6} \mathrm{H}_{4} \mathrm{OMe}-p$

\section{Scheme 8}

The synthetic strategy can be applied to the synthesis of chiral tricyclic pyrrolo[1,2c]thiazoles. The generation of 5-substituted-5H,7H-thiazolo[3,4-c]oxazol-4-ium-1-olates containing internal dipolarophiles involves the $N$-acylation of 2-substituted-thiazolidine-4carboxylates with the appropriate acid chloride as illustatred by the examples shown in Scheme 9. The reaction conditions used allowed the selective synthesis of $\mathrm{N}$-acylthiazolidines $\mathbf{2 9}$ with $(2 R, 4 R)$ stereochemistry which leads to the synthesis of pyrrolo[1,2-c]thiazole derivatives 32 with $R$ configuration. ${ }^{20}$<smiles>[R]C1N[C@@H](C(=O)OC)CS1</smiles><smiles>[Y]CC1=[N+]2C(=CC1CC)C(=O)OC2CC</smiles>

31<smiles>[R]C1SC[C@@H](C(=O)OC)N1C(=O)C[Y]([H])([H])C#C</smiles>

29<smiles>[Y]Cc1c([X])cc2n1[C@@H]([R])SC2</smiles>

32<smiles>[R]C1SC[C@@H](C(=O)O)N1C(=O)C[Y]([H])(C)C#CC</smiles>

30 a $n=1 ; R=P h ; X=O$
b $n=1 ; R=P h ; X=S$
c $n=1 ; R=M e ; X=O$
d $n=2 ; R=P h ; X=O$

\section{Scheme 9}

The reaction of ( $p$-methoxyphenyl)glyoxal and $L$-cysteine methyl ester gives as expected a thiazolidine as a mixture of the $(2 S, 4 R)$ - and $(2 R, 4 R)$-diastereoisomers. However, in this case the two diastereoisomers of methyl 2-(p-methoxyphenyl)thiazolidine-4-carboxylate can be separated by selective crystallisation proving that the interconversion of these isomers through a reversible ring opening mechanism is difficult. The reaction of each thiazolidine with prop-2-ynyloxyacetic acid chloride in presence of potassium carbonate leads to the corresponding $N$-acylthiazolidines (33 and 36) with retention of configuration at C-2. Using our synthetic strategy the chiral 5-( $p$ - 
methoxyphenyl)-1H-pyrrolo[1,2-c]thiazole 35 was obtained with $R$ configuration from 33 and its enantiomer, 5-( $p$-methoxyphenyl)-1H-pyrrolo[1,2-c]thiazole 38, from thiazolidine 36 (Scheme 10). ${ }^{20 \mathrm{~b}}$<smiles>COC(=O)N1C(C(=O)Br)CS[C@@H]1C(=O)Br</smiles>

33

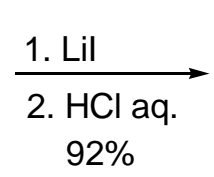

$92 \%$

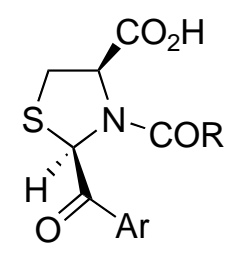

34

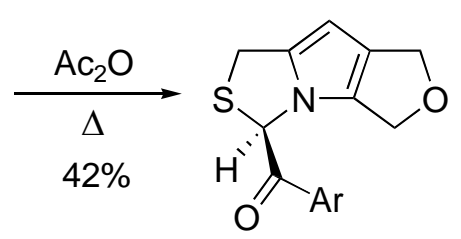

35<smiles>[R]OC1[C@H](C(C)=O)CS[C@H]1C([3H])=O</smiles>

36

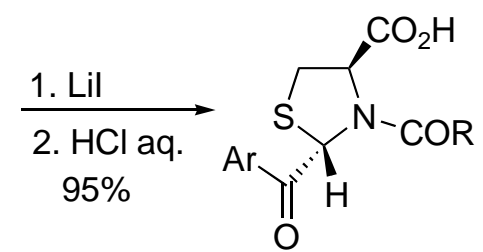

37

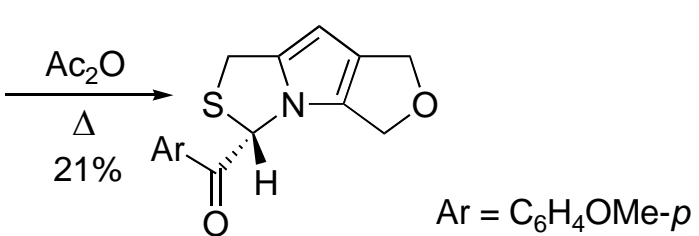

38
$\mathrm{R}=\mathrm{s}^{\mathrm{s}} \mathrm{V} \mathrm{O} / \mathrm{Y}$

\section{Scheme 10}

\subsection{Generation and Reactivity of Azafulvenium Methides}

The study of pericyclic reactions of extended dipoles (with more than $4 \pi$ electrons) is an almost unexplored research area. However, Storr and co-workers explored the reactivity of pyrrolo[1,2c]thiazole-2,2-dioxides and pyrazolo[1,5-c]thiazole-2,2-dioxides and proved that they can be considered as masked aza- and diazafulvenium methides (39 and 40). ${ }^{21}$ Earlier, Padwa and coworkers described unsuccessful attempts to extrude $\mathrm{SO}_{2}$ from pyrrolo[1,2-c]thiazole-2,2-dioxides for the generation of an azafulvenium methide, both thermally $\left(300{ }^{\circ} \mathrm{C}\right)$ and photochemically. ${ }^{22}$ These systems can be considered as "higher-order" azomethine ylides (39) or azomethine imines (40) and, in principle, can act as $4 \pi 1,3$-dipoles or as $8 \pi 1,7$-dipoles.

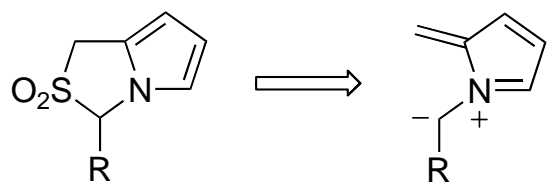

39

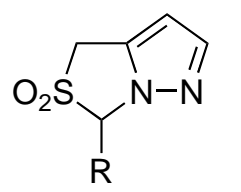

$\Longrightarrow$

Storr and co-workers found that the generation of 1-azafulvenium methides (41-44) by the thermal extrusion of sulfur dioxide from pyrrolo[1,2-c]thiazole-2,2-dioxides could be achieved under flash vacuum pyrolysis (FVP) reaction conditions. They described the first evidence for trapping of transient 1-azafulvenium methide systems (41-44) in pericyclic reactions. These extended dipolar systems 41-43 undergo sigmatropic $[1,8] \mathrm{H}$ shifts giving vinylpyrroles and the acyl derivatives $\mathbf{4 4}$ electrocyclise to give pyrrolo[1,2-c]-[1,3]oxazines. ${ }^{21}$ 
<smiles>[R]C([R])=C1C(C(C)=O)=C(C(C)=O)C(C)=[N+]1[CH]C</smiles>

$41 \mathrm{R}^{1}=\mathrm{R}^{2}=\mathrm{H} ; \mathrm{R}^{3}=\mathrm{CH}_{3}$

$42 \mathrm{R}^{1}=\mathrm{H} ; \mathrm{R}^{2}=\mathrm{CH}_{3} ; \mathrm{R}^{3}=\mathrm{H}$

$43 \mathrm{R}^{1}=\mathrm{R}^{2}=\mathrm{CH}_{3} ; \mathrm{R}^{3}=\mathrm{H}$

$44 \mathrm{R}^{1}=\mathrm{H} ; \mathrm{R}^{2}=\mathrm{COR} ; \mathrm{R}^{3}=\mathrm{H}$

In relation with our ongoing research on the synthesis of chiral $1 H, 3 H$-pyrrolo[1,2c]thiazoles, we became interested in exploring the generation of azafulvenium methides in order to get further knowledge on the reactivity of these transient $8 \pi$ 1,7-dipoles. ${ }^{23,24}$

We found that the vinylpyrrole 46 a could be obtained in $61 \%$ yield via azafulvenium methide $\mathbf{4 1}$ carrying out the reaction in a sealed tube allowing us to conclude that sulfone 45a extrudes sulfur dioxide without the need of FVP conditions. The flash vacuum pyrolysis of sulfone 45a was also studied. Interestingly our FVP conditions led to a different outcome than the previously reported result, ${ }^{21}$ the synthesis of methyl 1,3-dimethyl-5-oxo-5H-pyrrolizine-2carboxylate 47a. The pyrolysis of vinylpyrrole 46a also led to the efficient synthesis of compound 47a (79\%). Therefore, vinylpyrrole 46a is an intermediate in the formation of methyl 1,3-dimethyl-5-oxo-5H-pyrrolizine-2-carboxylate 17a from sulfone $\mathbf{4 5 a}$. The thermolysis of $\mathbf{4 5 b}$ carried out in a sealed tube led to $N$-vinylpyrrole $\mathbf{4 6 b}$ in $43 \%$ yield. On the other hand, compound 46b was converted into 5-oxo-5H-pyrrolizine 47b on FVP (44\%). The same product was obtained from the FVP of $\mathbf{4 5 b}$ (Scheme 11). ${ }^{23,24}$
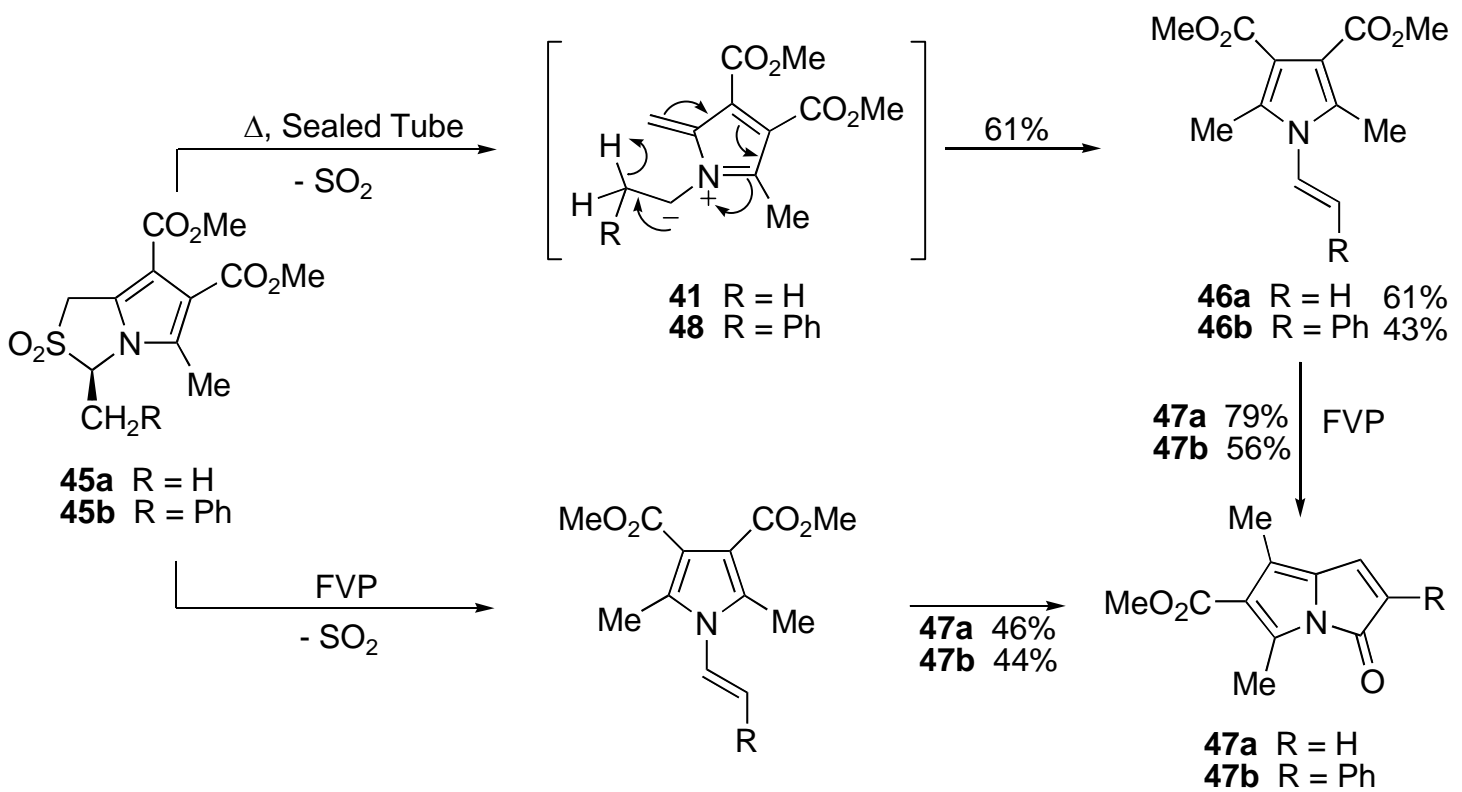

\section{Scheme 11}

The study was extended to other 3-alkyl pyrrolo[1,2-c]thiazole-2,2-dioxide derivatives. ${ }^{24}$ In the case of pyrrolo[1,2-c]thiazole 45c bearing an isopropyl group at C-3, the sealed tube 
thermolysis leads to pyrrole $\mathbf{4 9}$ in moderate yield. The two substituents at the terminus of the double bond of $\mathbf{4 9}$ preclude its conversion into a pyrrolizine. Thus, under FVP reactions conditions two products are obtained, the $N$-vinylpyrrole $\mathbf{4 9}$ and 6-oxo-cyclopenta[b]pyrrole 50, which structure was determined by X-ray crystallography (Scheme 12).

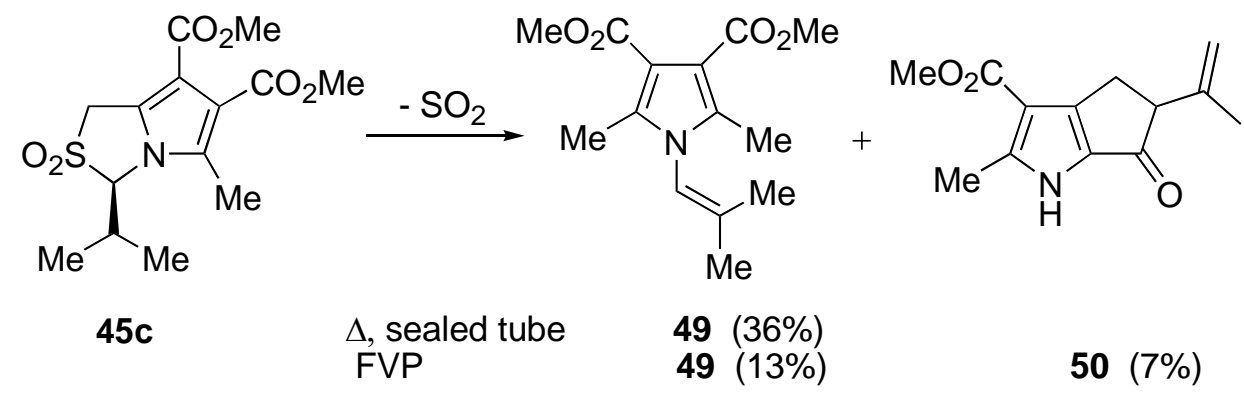

\section{Scheme 12}

The mechanism of conversion of pyrrolo[1,2-c]thiazole-2,2-dioxides into $N$-vinylpyrroles was proposed by Storr et al. who first reported the synthesis of $N$-vinylpyrrole 46a from the 1azafulvenium methide $\mathbf{4 1} .^{21}$ It is an allowed, suprafacial $[1,8] \mathrm{H}$ shift in the $8 \pi$ 1,7-dipolar system (Scheme 11).

The formation of 5-oxo-5H-pyrrolizines from $N$-vinylpyrroles can be rationalized as outlined in Scheme 13. It is known that 2-substituted 3-(pyrrol-2-yl)propionate methyl esters undergo concerted elimination of methanol on FVP to give pyrrol-2-ylideneketene intermediates which give pyrrolizinones by electrocyclisation. ${ }^{25}$ Thus, pyrrol-2-ylpropionates $\mathbf{5 1}$ must be intermediates in the synthesis of the 5-oxo-5 $\mathrm{H}$-pyrrolizines, formed from the $\mathrm{N}$-vinylpyrroles through a sequence of sigmatropic shifts. The pyrrol-2-ylpropionates undergo concerted elimination of methanol giving pyrrol-2-ylideneketenes 52, which are converted into pyrrolizinones by electrocyclisation.

The thermolysis of 3-phenyl-1H-pyrrolo[1,2-c]thiazole-2,2-dioxides 45d and 45e was also studied (Scheme 14). We found that the cheletropic extrusion of $\mathrm{SO}_{2}$ from these sulfones could be carried out in a sealed tube leading to styryl- $1 H$-pyrroles (55). The formation of styryl- $1 H$ pyrroles 55 can be explained considering the generation of azafulvenium methides (53) followed by an 1,7-electrocyclic reaction giving $\mathbf{5 4}$, which rearrange to the final products. Sulfone $\mathbf{4 5 d}$ is converted into methyl 2-methyl-4-oxo-1,4-dihydro-1-aza-benzo[f]azulene-3-carboxylate 56a on flash vacuum pyrolysis. Under these reaction conditions styryl- $1 H$-pyrrole 55a is formed and converted into a pyrrole fused to a benzocyclohepten-5-one ring system. This was confirmed by promoting the FVP of styryl- $1 H$-pyrrole 55a, which also gave compound 56a (31\%). 3-Phenyl$1 H$-pyrrolo[1,2-c]thiazole-2,2-dioxide 45e and styryl-1H-pyrrole 55b showed similar chemical behavior when compared with 45d and 55a respectively, and the corresponding 4-oxo-1,4dihydro-1-aza-benzo[f]azulene-3-carboxylate $\mathbf{5 6 b}$ could be obtained on FVP, although in low yield. 


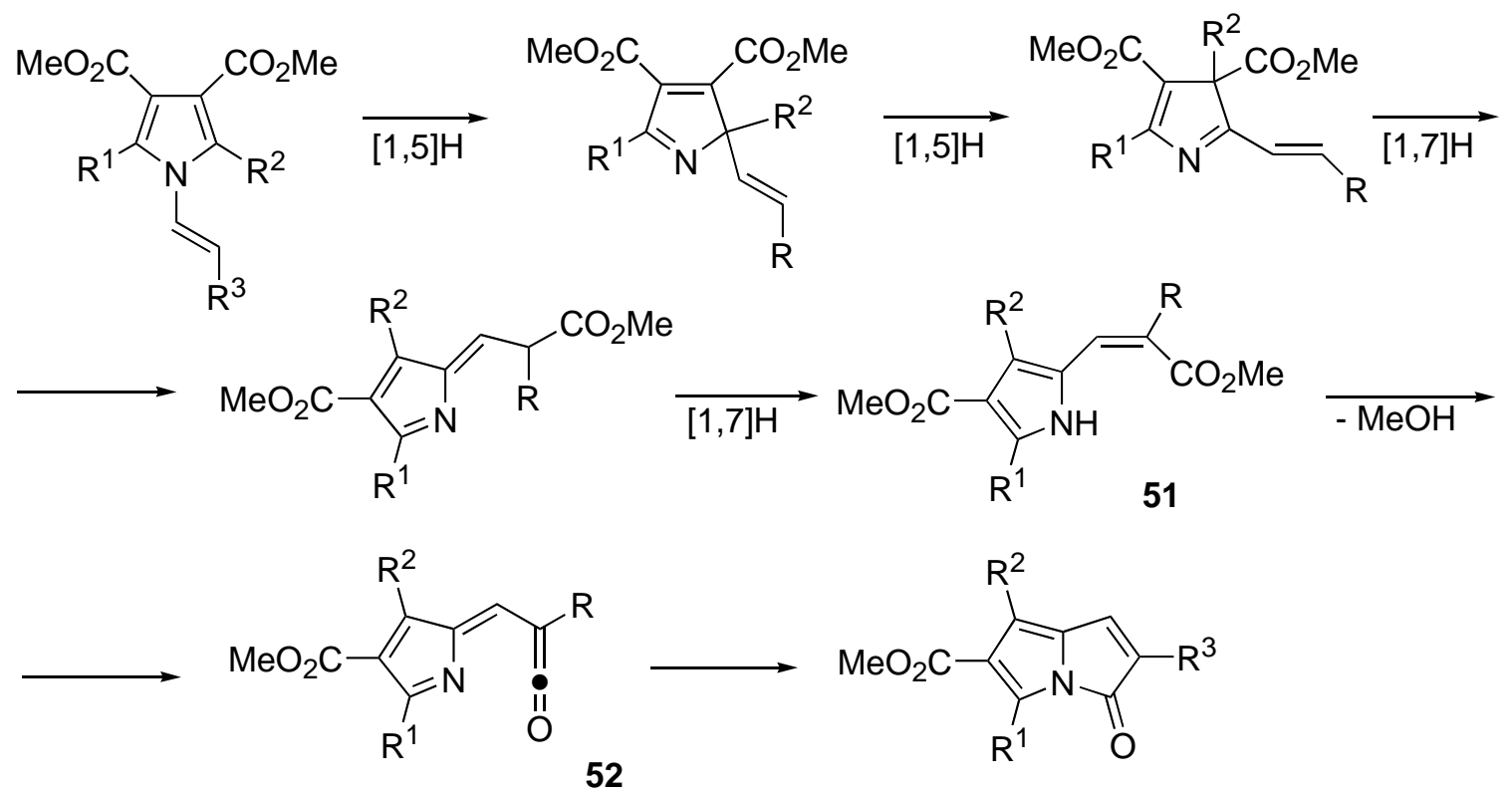

\section{Scheme 13}
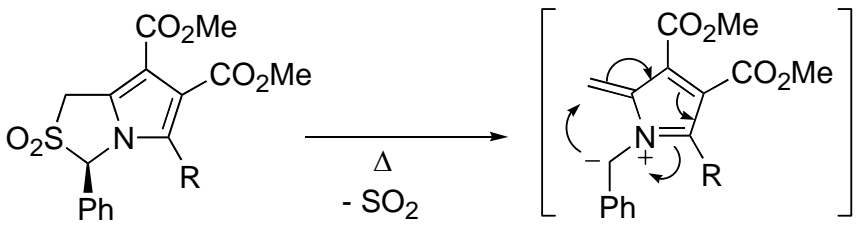

Sealed Tube

45d $\mathrm{R}=\mathrm{Me}$ 45e $\mathrm{R}=\mathrm{Ph}$
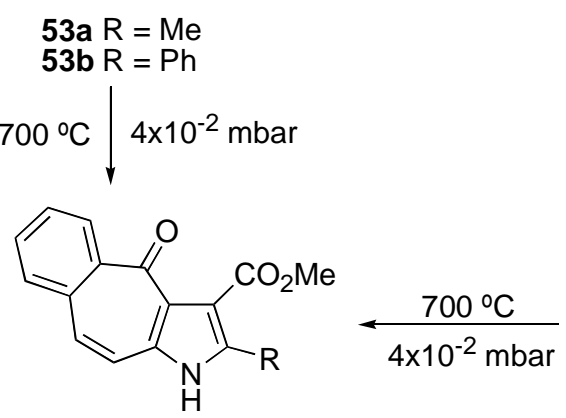

$56 a \quad R=M e 22 \%($ from $63 a)$

$56 \mathrm{~b} R=\mathrm{Ph} \begin{array}{r}31 \%(\text { from } 78 \mathrm{a}) \\ 2 \%(\text { from } 63 \mathrm{i})\end{array}$

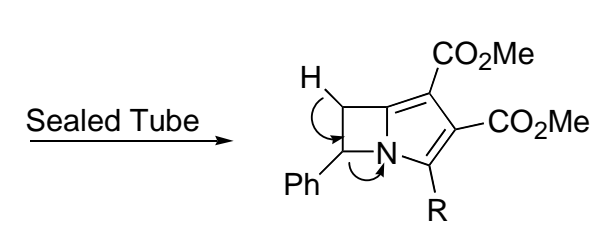

54a $\quad \mathrm{R}=\mathrm{Me}$

$54 \mathrm{~b} \quad \mathrm{R}=\mathrm{Ph}$<smiles>[R]c1[nH]c(/C=C/c2ccccc2)c(C(C)=O)c1C(=O)OC</smiles>

$55 \mathrm{a} \quad \mathrm{R}=\mathrm{Me} \quad 54 \%$

55b $\quad \mathrm{R}=\mathrm{Ph} \quad 80 \%$

\section{Scheme 14}

The mechanism for the formation of $\mathbf{5 6}$ is shown in Scheme 15. The styryl-1H-pyrrole 55 generates pyrrol-3-ylketene 57 on eliminating methanol. Electrocyclisation of $\mathbf{5 7}$ followed by two sigmatropic H-shifts gives compounds $\mathbf{5 6 .}$ 


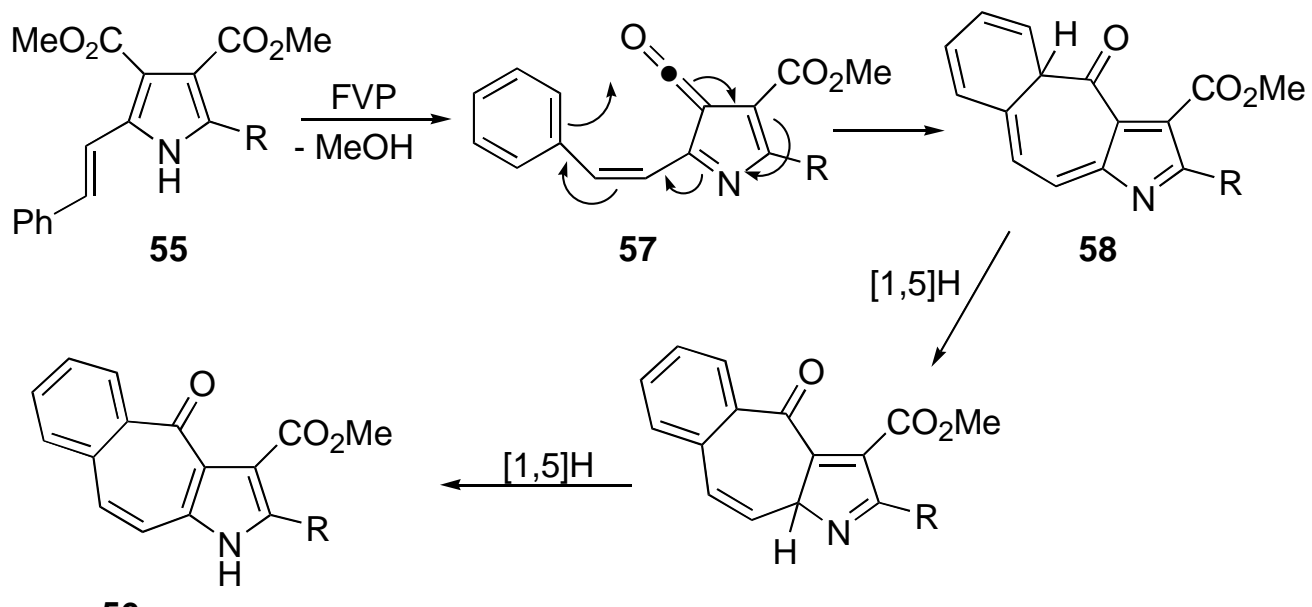

56

59

\section{Scheme 15}

Padwa et al. reported unsuccessful attempts to extrude sulfur dioxide from pyrrolo[1,2c] thiazole-2,2-dioxide $\mathbf{4 5 f}$ by solution-phase thermolysis $\left(300{ }^{\circ} \mathrm{C}\right) .{ }^{22}$ Storr et al. considering that this unsuccessful result was due to the high thermal stability of this sulfone, characterized by low bond order of the 3,4-bond of the sulfolene moiety, attempted the flash vacuum pyrolysis. $^{21}$ Although sulfur dioxide was eliminated from sulfone $\mathbf{4 5 f}$ no identifiable products were detected. However, we observed that under our FVP conditions two products are obtained from pyrrolo[1,2-c]thiazole-2,2-dioxide 45f, the $C$-vinylpyrrole 60 and 5-oxo-5H-pyrrolizine 61, although in low yield (Scheme 16). ${ }^{24}$

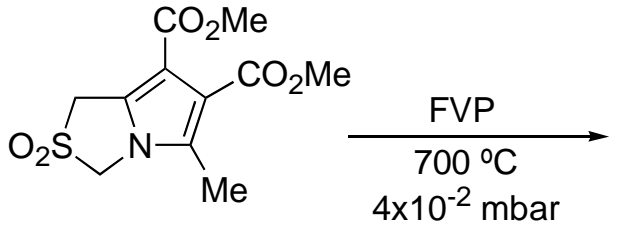

$45 f$<smiles>C=Cc1[nH]c(C)c(C(C)=O)c1C(C)=O</smiles>

$6010 \%$<smiles>COC(=O)c1cc2n(c1C)C(=O)C=C2</smiles>

$618 \%$

\section{Scheme 16}

The 1-azafulvenium methide (62) does not have a proton in the appropriate position to allow the suprafacial $[1,8] \mathrm{H}$ shift of the type described in Scheme 11 for the synthesis of $N$ vinylpyrroles. Therefore, the process occurs via an alternative route, an 1,7-electrocyclic reaction gives 63 which undergoes a rearrangement to pyrrole 60. This is in fact, a mechanism pathway similar to the one described for the phenyl derivatives 55. The mechanistic interpretation for the synthesis of 5-oxo-5H-pyrrolizine $\mathbf{6 1}$ from $\mathbf{6 0}$ is also outlined in Scheme $17 .^{24}$ 

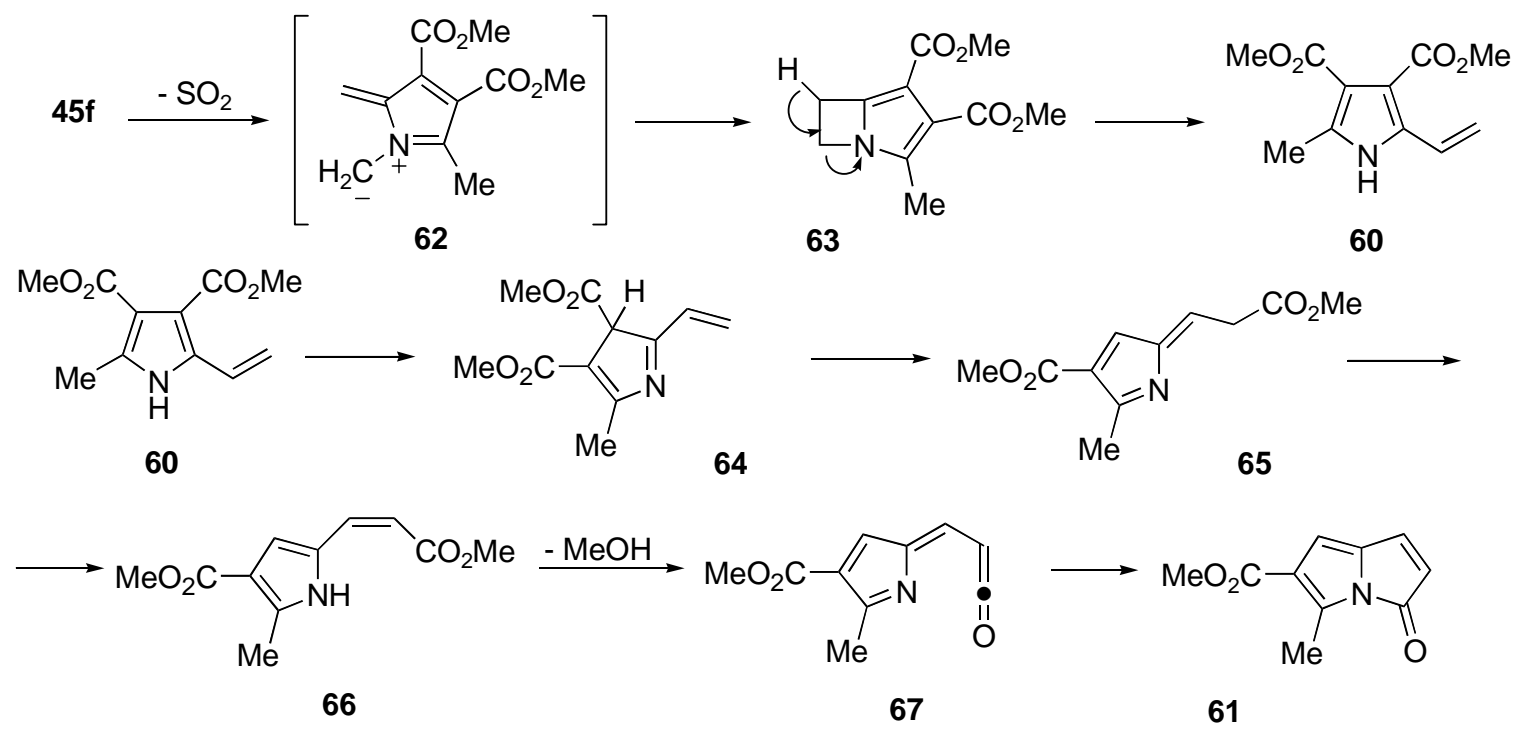

\section{Scheme 17}

It has been reported that pyrazole derivative $\mathbf{6 8}$ undergoes $\mathrm{SO}_{2}$ extrusion in solution and the corresponding 1,2-diazafulvenium methide 69 does not react with $\mathrm{N}$-phenylmaleimide or dimethyl acetylenedicarboxylate but can be intercepted in $8 \pi+2 \pi$ cycloaddition with silylated acetylenes giving adducts resulting from the addition across the 1,7-position. ${ }^{21}$ We also observed that 1,2-diazafulvenium methide $\mathbf{6 9}$ can be trapped by reacting with bis(trimethylsilyl)acetylene, confirming the reported result. However, the dipolar system 69 also participates in the cycloaddition with $N$-phenylmaleimide giving the corresponding cycloadduct in $87 \%$ yield (Scheme 18). ${ }^{26}$

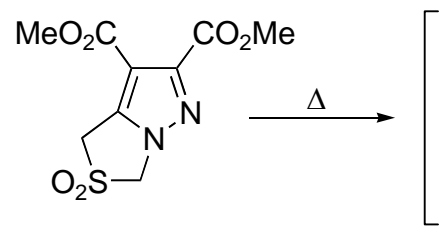

68

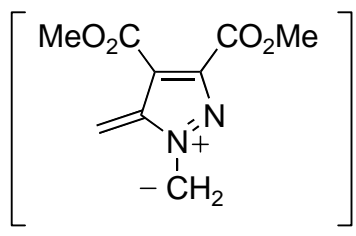

69

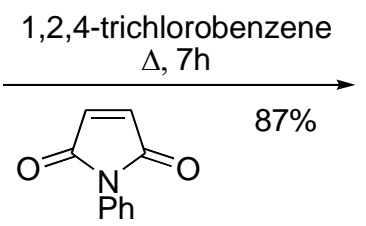

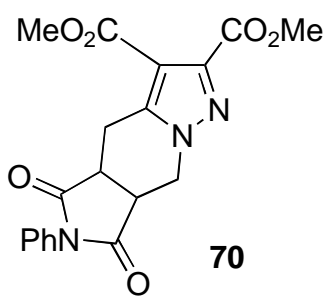

\section{Scheme 18}

We decided to explore the possibility of generating new diazafulvenium methides systems and study their reactivity in the absence of dipolarophiles. Carrying out flash vacuum pyrolysis of 3-methyl-pyrazolo[1,5-c]thiazole-2,2-dioxide 71 at $500{ }^{\circ} \mathrm{C}$ we obtained 1-vinyl-1H-pyrazole 73 selectively via the diazafulvenium methide $\mathbf{7 2}$, which was trapped in an intramolecular sigmatropic [1,8]H shift (Scheme 19). ${ }^{26}$ 


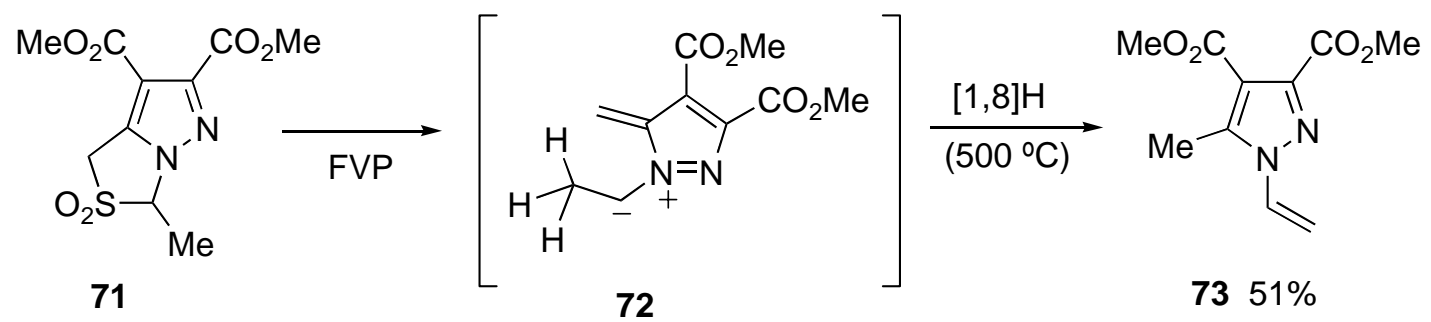

\section{Scheme 19}

The 3-methyl-pyrazolo[1,5-c]thiazole-2,2-dioxide 71 undergoes also $\mathrm{SO}_{2}$ extrusion by solution-phase thermolysis to give 72 , which can be intercepted in $8 \pi+2 \pi$ cycloadditions with $N$ phenylmaleimide and dimethyl acetylenedicarboxylate giving adducts resulting from the addition across the 1,7-positions in high yields. An attempt to react $\mathbf{7 2}$ with bis(trimethylsilyl)acetylene led only to the synthesis of 1 -vinyl-1H-pyrazole 73 in $16 \%$ yield. $^{26}$

\section{Conclusions}

1,3-Thiazolidines are interesting precursors of reactive intermediates namely azadienes, and dipoles, which in turn are useful heterocycles building blocks. Exploring thiazolidines' diastereoselective reactions allows the development of routes to chiral heterocyclic compounds, including 1,3-thiazolidine-annulated systems and pyrrolo[1,2-c] thiazoles.

Pyrrolo[1,2-c]thiazole-2,2-dioxides and pyrazolo[1,5-c]thiazole-2,2-dioxides are masked aza- and diazafulvenium methides. The intramolecular trapping of the transient azafulvenium methides in pericyclic reaction, namely sigmatropic [1,8] H shifts and 1,7-electrocyclization, leads to the synthesis of $N$-vinylpyrroles and $C$-vinylpyrroles. Under FVP conditions the vinylpyrroles are converted into heterocycles where another ring system is annulated to pyrrole, such as 5-oxo-5H-pyrrolizines and 4-oxo-1,4-dihydro-1-aza-benzo[f]azulenes. The synthesis of these heterocycles can also be directly achieved from the flash vacuum pyrolysis of pyrrolo[1,2c]thiazole-2,2-dioxides. The $\mathrm{SO}_{2}$ extrusion of pyrazolo[1,5-c]thiazole-2,2-dioxides occurs more easily than from the analogous pyrrolo sulfones and can be carried out in refluxing 1,2,4trichlorobenzene. The diazafulvenium methides, generated by this way, can be intercepted in $8 \pi+2 \pi$ cycloadditions giving adducts resulting from the addition across the 1,7-position. In the absence of dipolarophiles the 1-methyl-diazafulvenium methide, generated under FVP reaction conditions, undergoes an intramolecular sigmatropic [1,8] $\mathrm{H}$ shift giving a 1-vinyl- $1 \mathrm{H}$-pyrazole derivative. 


\section{Acknowledgements}

Financial support from Chymiotechnon and FCT (POCI/QUI/55584/2004) is gratefully acknowledged.

\section{References}

1. Öhler, E.; Schmidt, U. Chem. Ber. 1979, 112, 107.

2. (a) Gilchrist, T. L.; Gonsalves, A. M. d'A. R.; Pinho e Melo, T. M. V. D. Tetrahedron Lett. 1993, 34, 4097. (b) Gilchrist, T. L.; Gonsalves, A. M. d'A. R.; Pinho e Melo, T. M. V. D. Tetrahedron 1994, 50, 13709. (c) Gilchrist, T. L.; Gonsalves, A. M. d'A. R.; Pinho e Melo, T. M. V. D. Pure \& Appl. Chem. 1996, 68, 859.

3. Pinho e Melo, T. M. V. D.; Fausto, R.; Gonsalves, A. M. d'A. R.; Gilchrist, T. L. J. Org. Chem. 1998, 63, 5350.

4. Gilchrist, T. L.; Gonsalves, A. M. d'A. R.; Pinho e Melo, T. M. V. D. Tetrahedron Lett. 1993, 34, 6945.

5. Pinho e Melo, T. M. V. D.; Cabral, A. M. T. D. P. V.; Gonsalves, A. M. d'A. R.; Beja, A. M.; Paixão, J. A.; Silva, M. R.; Alte da Veiga, L. J. Org. Chem. 1999, 64, 7229.

6. Zaima, T.; Matsunaga, Y.; Mitsuhashi, K. J. Heterocycl. Chem. 1983, $20,1$.

7. Gelas-Mialhe, Y.; Mabiala, G.; Vessière, R. J. Org. Chem. 1987, 52, 5395.

8. (a) Zaima, T.; Matsuno, C.; Matsunaga, Y.; Mitsuhashi, K. J. Heterocycl. Chem. 1984, 21, 445. (b) Zaima, T.; Matsuno, C.; Matsunaga, Y.; Mitsuhashi, K. Nippon Kagaku Kaishi 1984, 1293; Chem. Abstr. 1984, 101, 230340.

9. Zaima, T.; Mitsuhashi, K. Nippon Kagaku Kaishi 1979, 901; Chem. Abstr. 1979, 91, 140303.

10. Zaima, T.; Matsuno, C.; Mitsuhashi, K. Nippon Kagaku Kaishi 1983, 152; Chem. Abstr. 1983, 98, 179141.

11. (a) Pinho e Melo, T. M. V. D.; Santos, C. I. A.; Rocha Gonsalves, A. M. d'A.; Paixão, J. A.; Beja, A. M.; Silva, M. R. Tetrahedron Lett. 2003, 44, 8285. (b) Pinho e Melo, T. M. V. D.; Santos, C. I. A.; Rocha Gonsalves, A. M. d'A.; Paixão, J. A.; Beja, A. M. Tetrahedron 2004, 60, 3949.

12. Allin, S. M.; Vaidya, D. G.; Page, M. I.; Slawin, A. M. Z. ARKIVOC 2000, 1, 151.

13. Oliver, G. L.; Gates, Jr., J. W. J. Am. Chem. Soc. 1958, 702.

14. (a) Takahashi, I.; Kawakami, T.; Hirano, E.; Yokota, H.; Kitajima, H. Synlett 1996, 353. (b) Mertens, A.; Zilch, H.; König, B.; Schäfer, W.; Poll, T.; Kampe, W.; Seidel, H.; Leser, U.; Leinert, H. J. Med. Chem. 1993, 36, 2526. (c) Schäfer, W.; Friebe, W.-G.; Leinert, H.; Mertens, A.; Poll, T.; Saal, von der W.; Zilch, H.; Nuber, B.; Ziegler, M. L. J. Med. Chem. 1993, 36, 726. (d) Clercq, E. J. Med. Chem. 1995, 38, 2491. (e) Allin, S. M.; Vaidya, D. G.; Page, M. I.; Slawin, A. M. Z.; Smith, T. Tetrahedron Lett. 2000, 41, 2219. 
15. Hiskey, R. G.; Dominianni, S. J. J. Org. Chem. 1965, 30, 1506.

16. 1,3-Thiazolidine-4-carboxylic Acids as Building Blocks in Organic Synthesis, Teresa M. V. D. Pinho e Melo In Targets in Heterocyclic Systems - Chemistry and Properties, Attanasi, A.; Spinelli, D., Eds., Italian Society of Chemistry, 2004; Vol.8, pp 288-329.

17. Györgydeák, Z.; Szilágyi, L.; Kajtár, J.; Argay, G.; Kálmán, A. Monatsh. Chem. 1994, 125, 189.

18. Pinho e Melo, T. M. V. D.; Soares, M. I. L.; Barbosa, D. M.; Rocha Gonsalves, A. M. d'A.; Matos Beja, A.; Paixão, J. A.; Ramos Silva, M.; Alte da Veiga, L. Tetrahedron 2000, 56, 3419.

19. Pinho e Melo, T. M. V. D.; Gomes, C. S. B.; Rocha Gonsalves, A. M. d'A.; Paixão, J. A.; Matos Beja, A.; Ramos Silva, M.; Alte da Veiga, L. Tetrahedron 2002, 58, 5093.

20. (a) Pinho e Melo, T. M. V. D.; Barbosa, D. M.; Ramos, P. J. R. S.; Rocha Gonsalves, A. M. d'A.; Gilchrist, T. L.; Matos Beja, A.; Paixão, J. A.; Ramos Silva, M.; Alte da Veiga, L.; J. Chem. Soc. Perkin Trans. I 1999, 1219. (b) Pinho e Melo, T. M. V. D.; Soares, M. I. L.; Rocha Gonsalves, A. M. d'A.; Paixão, J. A.; Matos Beja, A.; Ramos Silva, M. J. Org. Chem. 2002, 67, 4045.

21. (a) Sutcliffe, O. B.; Storr, R. C.; Gilchrist, T. L.; Rafferty, P.; Crew, A. P. A. Chem.Comm. 2000, 675-676; (b) Sutcliffe, O. B.; Storr, R. C.; Gilchrist, T. L.; Rafferty, P. J. Chem. Soc. Perkin Trans. 1 2001, 1795-1806.

22. Padwa, A.; Fryxell, G. E.; Gasdaska, J. R.; Venkatramanan, M. K.; Wong, G. S. K. J. Org. Chem. 1989, 54, 644-652.

23. Pinho e Melo, T. M. V. D.; Soares, Maria I. L.; Rocha Gonsalves, A. M. d'A. McNab, H. Tetrahedron Lett. 2004, 45, 3889-3893.

24. Pinho e Melo, T. M. V. D.; Soares, Maria I. L.; Rocha Gonsalves, A. M. d'A.; Paixão, J. A.; Matos Beja, A,; Ramos Silva, M. J. Org. Chem. 2005, 70, 6629-6638.

25. McNab, H.; Parson, S.; Stevenson, E. J. Chem. Soc. Perkin Trans. I 1999, 2047-2048.

26. Pinho e Melo, T. M. V. D.; Soares, M. I. L.; Rocha Gonsalves, A. M. d'A. Tetrahedron Lett. 2006, 791-794. 